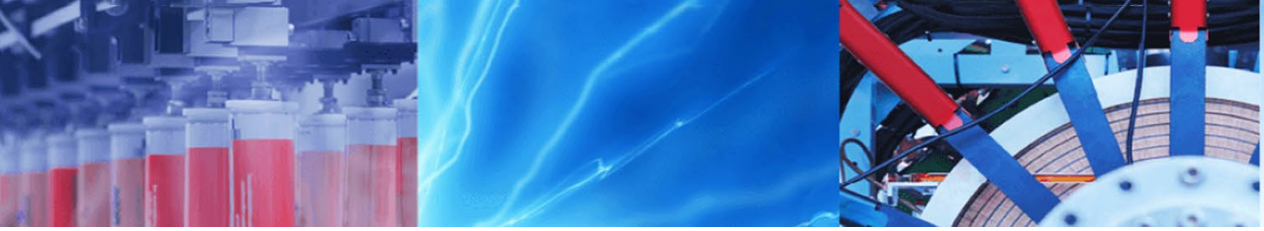

Research Article

\title{
Mechanical performance of lightweight ceramic structures via binder jetting of microspheres
}

\author{
Bhargavi Mummareddy ${ }^{1}$ (I) $\cdot$ Edward Burden $^{1} \cdot$ J. G. Carrillo ${ }^{2} \cdot$ Kyle Myers $^{3} \cdot$ Eric MacDonald $^{1} \cdot$ Pedro Cortes $^{1}$
}

Received: 18 July 2020 / Accepted: 18 February 2021 / Published online: 2 March 2021

(C) The Author(s) 2021 OPEN

\begin{abstract}
Geometrically-complex and lightweight ceramic parts manufactured via 3D printing are prospective structures that seem to provide excellent thermal, wear and dielectric performance. In the present work, binder jetted parts based on synthetic lightweight ceramic hollow microspheres were manufactured and evaluated under different testing conditions in order to characterize their mechanical performance. The resulting structures were assessed in terms of quasi-static flexural and compressive strength, and density. Furthermore, microscopy analyses highlighted the composition of the final structures and fracture mechanisms. The printed system mainly consisted of aluminum silicon dioxide, fly ash and traces of metal. The samples yielded similar strength as that achieved on conventional bulk-based 3D printed ceramic structures. It was observed that the strength of the printed microspheres increased by sintering the parts to near-fusion temperatures due to viscous flow of material during sintering. The combination of the proposed process and feedstock represents an attractive manufacturing method for fabricating lightweight structures for applications like composite tooling molds, electromagnetic devices, and biomedical implants.
\end{abstract}

Keywords Additive manufacturing $\cdot$ Binder jetting $\cdot$ Microspheres $\cdot$ Ceramics $\cdot$ Lightweight ceramics

\section{Introduction}

Ceramics are attractive material systems employed in a diversity of industries given the unique mechanical, dielectric and thermal properties under corrosive, high temperature and harsh environmental conditions [1, 2]. More specifically, lightweight ceramics are beneficial for both the aerospace and automobile industries, in which weight reduction is paramount for fuel efficiency. However, these industries simultaneously require durability, energy absorption, both thermal and acoustic insulation [1]. On the other hand, lightweight ceramic powders, used as feedstock in several additive manufacturing processes, are hard to process due to their low specific gravities and high melting points, particularly for geometrically-complex 3D printed ceramic structures [2]. Despite these challenges, significant research is focused on exploring the simultaneous benefits of ceramic materials in the context of additive manufacturing [1, 3, 4]. All seven sub-processes of additive manufacturing as described by the ISO/ASTM F52900 standard [5] have demonstrated the fabrication of ceramic parts with varying degrees of success [6-18] and the remaining challenges are related in obtaining dense parts and avoiding cracking.

The most effective technologies used in additive manufacturing for producing ceramic parts is via binder jetting printing, stereolithography, material jetting and selective laser sintering $[7,18,19]$. All of these additive techniques use ceramic powder as the feedstock and are based on a similar building process where fabricating the printed

\footnotetext{
$\triangle$ Bhargavi Mummareddy, bmummareddy@student.ysu.edu | ${ }^{1}$ Advanced Manufacturing Research Center, Youngstown State University, Youngstown, $\mathrm{OH}, \mathrm{USA} .{ }^{2}$ Materials Department, Centro de Investigacion Cientifica de Yucatan, 97205 Mérida, Mexico. ${ }^{3}$ The ExOne Company, North Huntingdon, PA, USA.
} 
structure occurs in a layer-by-layer fashion according to a sliced CAD model. The manufacturing process of printed part is achieved by either selectively depositing a binder during the building process or using other direct sources of energy to fuse the powder with or without the requirement of post-processing sintering $[19,20]$. Processed ceramics are one of the interesting materials for industrial applications due to thermal stability. Among such materials, hollow microspherical powders with thin walls appear to represent an attractive ceramic systems for cast furniture, naval cements and gaskets [21]. In addition to their broad applications, the microspheres have a low density which represents a light mass in contrast to using solid ceramics powders. The cavity feature in these powders enables the 3D printing of lightweight ceramics [22]. Ceramic Hollow Microspheres are primarily used as raw material, additives, coatings, abrasions, dispersing agents and fillers in masonry mixtures [1, 23-27]. Tao et al. [24] studied the mechanical behaviour of unimodal and bimodal Al ceramic-hollow microsphere syntactic foams that were produced via melt casting and concluded that the powders were a suitable choice for energy absorption applications. The usage of microspheres shows a higher strain on densification. Additional studies have investigated the high energy absorption capabilities of alumina hollow microspheres under ballistic conditions [28-30]. It was also seen that the strength and non-dependent strain bearing properties depend on the wall-thickness-to-diameter ratios $[29,30]$ in which greater cavity diameters offer better performance. It has also been demonstrated that ceramic hollow microspheres can be used as lightweight thin microwave absorbers by coating the printed ceramic structure with ferrites as well as with a conductive Co-Fe thin layer [4, 31]. The usage of Co-Fe film enables easy magnetization of ceramic particles. Fly Ash hollow spheres (FAHS) fabricated by stack-sintering and gel-casting techniques have shown noticeable increase in compressive strength despite thin walls, highlighting the suitability of the material for applications such as thermal and acoustic insulators, fluid filters and matrix foams [32]. Alumina based thin-walled hollow spheres were also investigated for applications in deep sea modules as these structures display a strong compressive performance accompanied with lightweight [33].

Alumina-silicate powders have been extensively studied for high density applications due to their exceptional properties in applications such as: electrical insulators, high frequency furnaces, turbine engine components, and infrared transparent windows [34-37]. These materials have been 3D printed, and subsequently infiltrated with metals in order to form interpenetrating phase composites (IPC's) [6, 38-40]. Spoerk et al. [41] used glass microspheres, which are essentially alumina-silicates, to enhance the interfacial adhesion and printability of polypropylene parts during the material extrusion printing process resulting in an increased impact strength. Additional studies have demonstrated that adding small amounts of metal oxides such as titania, ferrous oxide and zirconia to aluminum-silicates can increase their mechanical properties as a result of dendritic growth [42, 43]. The present work describes the mechanical properties of 3D printed hollow lightweight ceramic structures composed of alumina-silicate microspheres (see Fig. 1). The present study also provides a thermal and physical analysis of the hollow ceramic printed parts with the purpose of providing the foundation of fabricating complex lightweight ceramic parts that can be employed in the automotive, aerospace, tooling and surface coating refractory industries.

This paper is outlined as follows: Sect. 1 presented the literature review on 3D printed ceramics. Section 2 focuses on the printing technique and parameters used in this work, as well as on the description of the analytical techniques here used. Section 3 presents the experimental results and discussion of the thermal and mechanical performance of the investigated material. Included in this section, is the comparison of the studied 3D printed samples against other works based on either alternative 3D printed ceramics or bulk samples produced through traditional manufacturing processes. Finally, the conclusions of the study are presented in Sect. 4.

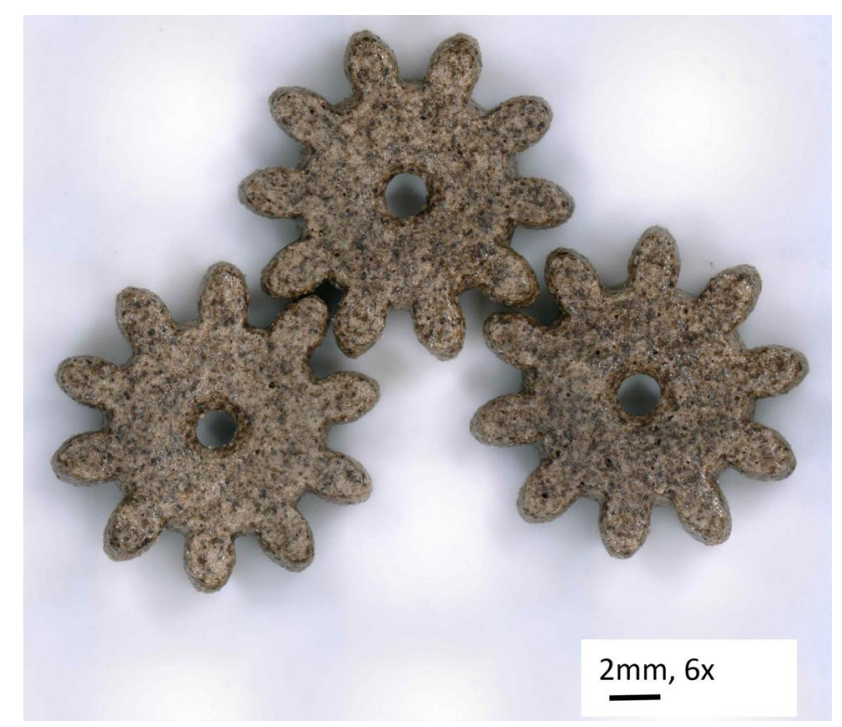

Fig. 1 Example of detailed lightweight and high-temperature printed parts based on hollow ceramic spheres 


\section{Experimental methodology}

\subsection{Materials}

Synthetic lightweight ceramic hollow microspherical powder from SphereOne, Inc. (Chattanooga, TN) with an average particle size of 75 microns was used in this work. The powder was described to provide flame retardancy, refractory behavior, corrosion and abrasion resistance. The specific gravity of the powder was reported as $0.75 \mathrm{~g} / \mathrm{cm}^{3}$ and the bulk density $0.40 \mathrm{~g} / \mathrm{cm}^{3}$. The initial XRF analysis on the as-received material showed that the spheres are composed of oxides of aluminum ( $\mathrm{Al}-32 \%)$, silicon ( $\mathrm{Si}-42.5 \%$ ) with trace amounts of $\mathrm{Fe}_{2} \mathrm{O}_{3}, \mathrm{CaO}_{2}, \mathrm{TiO}_{2}$.

\subsection{Manufacturing process}

An ExOne Innovent + binder jetting printer was used in this work for printing the samples in the $X, Y, Z$ directions following the ASTM 52921, as represented in Fig. 2. All samples were printed using a furan-based aqueous binder (\#7100037CL, BA005, ExOne, PA) and using parameters: $60 \%$ binder saturation with $5 \mathrm{~mm} / \mathrm{sec}$ roller traverse speed, and $150 \mu \mathrm{m}$ layer thickness aided by a drying time of $20 \mathrm{~s}$. From the literature, near full density parts were obtained from $60 \%$ binder saturation and relatively lower traverse speeds and layer thickness of approximately double the particle size $[44,45]$. Here, binder saturation is defined as the ratio of volume occupied by the binder to the volume of open pores in the powder [44]. Therefore, in this case $60 \%$ of the void volume is occupied by the binder with the assumption of powder packing of $100 \%$. The printed parts were initially cured (green state) in a conventional furnace for six hours at $180^{\circ} \mathrm{C}$ for hardening the binder. Subsequently, the parts were post-processed in air at $1275^{\circ} \mathrm{C}$ at a heating ramp rate of $7{ }^{\circ} \mathrm{C} / \mathrm{min}$ and a dwelling time of 30 min (sintered state). After the dwelling time, the samples were air cooled to room temperature. The purpose of investigating the green state was to establish a baseline on the physical and mechanical performance of the sintered parts. Green parts are commonly characterized to evaluate the effect printing parameters such as tap density and binder saturation, which have a direct impact on the performance of sintered parts $[46,47]$.

\subsection{Microstructural properties}

The particle size distribution of the as-received microspheres were characterized using a CILAS 1190 laser particle size analyzer. The density of the cured and sintered parts, as well as the shrinkage of the sintered samples was also investigated. The powder was tested with X-ray tomography to study the crystallinity of the material before and after printing on a Bruker Prospector CCD Diffractometer, which includes a $40 \mathrm{kV} X$-ray source. In addition, the sintered and fractured parts were observed under a Keysight FE-SEM equipped with EDS to investigate their structure-performance relationship.

\subsection{Mechanical and thermal characterization}

Quasi-static mechanical testing of the sintered parts was carried out on a Universal Instron machine. The ASTM C1424 and C1161 were followed for determining the compressive and flexural strengths, respectively, by testing four samples of each configuration. The compression and flexural testing of the samples was implemented at a cross-head displacement rate of $0.5 \mathrm{~mm} / \mathrm{min}$. The fracture toughness of the parts was also analyzed on the aforementioned equipment at a strain rate of $0.5 \mathrm{~mm} / \mathrm{min}$ using a three-point bending fixture following the ASTM C1421.
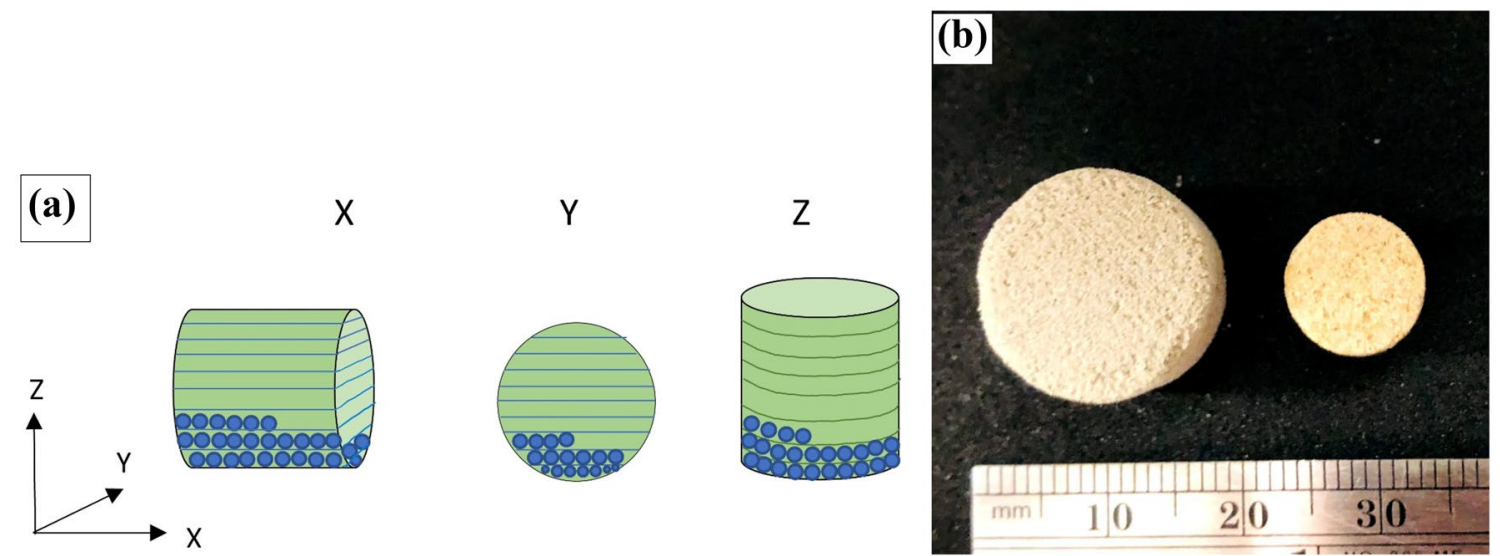

Fig. 2 (a) Schematic diagram of parts printed in different directions. (b) Green and sintered parts 
Here, the samples were polished with a 400 grit sandpaper to remove surface defects. A $0.005 \mathrm{~mm}$ thick blade was used to introduce a Single-edge-notch, resulting in a "a/w" ratio of 0.4 and a " $g(a / W)$ " function of the ratio $(a / W)$ reported to be 0.7 . After introducing the notch, the samples were observed in a high magnification microscope to ensure a uniform notch without construction errors. Vickers Hardness was also carried out on the sintered samples using a United Vickers Hardness Testing System with $10 \mathrm{~kg}$ force following the ASTM C1327. The samples were ground and polished to obtain a smooth surface for hardness testing. Finally, a TA Instruments Q400EM was used to determine the Coefficient of Thermal Expansion (CTE) for the sintered parts following the ASTM E831-06. The parts were subjected to a load of $0.2 \mathrm{~N}$ from a temperature of $25^{\circ} \mathrm{C}$ up to $500^{\circ} \mathrm{C}$ with a ramp rate of $5^{\circ} \mathrm{C} / \mathrm{min}$. An abrasive wear test on six sintered samples was also performed on a Struers Planopol grinder at $150 \mathrm{rpm}$, with an applied force of $10 \mathrm{~N}$, using a $600 \mu \mathrm{m}$ grit sized SiC grinding paper. The dimensions of the samples were examined at the 5,15 , 30 and 60 min intervals to evaluate their degree of wear.

\section{Results and discussion}

The particle size analysis of the as-received material is shown in Fig. 3. It was observed that the spherical particles had an average diameter of $34.2 \mu \mathrm{m}$. Spherical morphology, in conjunction with low specific gravity, are important features for enhancing the flowability of the particles during the printing process [47]. Unlike other small sized powders, these spherical particles had a good spread-ability, which was beneficial for printing complex parts. XRD analysis of the microspheres resulted in a composition based on $40.34 \%$ Alumina, $42.5 \%$ Silica, $6.2 \%$ Titanium Dioxide and traces of other metal oxides of $\mathrm{K}, \mathrm{Ca}$, Fe with $9.7 \%$ of crystallinity. It was also determined that the printed green parts had a density of $0.34 \mathrm{~g} / \mathrm{cm}^{3}$, while the sintered parts yielded a density of $1.002 \mathrm{~g} / \mathrm{cm}^{3}$; a value that is almost 3 times higher than the observed on the green parts.

Shrinkage analysis was also performed on the printed parts after being sintered, and it was observed that the samples yielded $28.80,26.72$ and $32.48 \%$ of reduction in the $X, Y$ and $Z$ directions, respectively. The standard deviation of the shrinkage was seen to be $1.99 \%, 3.73 \%$ and $2.65 \%$ for $X, Y$ and $Z$ directions respectively. The larger degree of shrinkage in the $Z$-direction, can be associated to the spacing that is created by the powder-binder interaction, in such direction. Indeed, the two reasons that lead to porosity are (i) jetting of binder on the build powder surface, where powder is removed by a ballistic effect, and (ii) viscous flow during the sintering process $[48,49]$. A similar behavior has been reported by Myers [50] and Parab et al. $[50,51]$ after sintering $3 \mathrm{D}$ printed $\mathrm{SiO}_{2}$ parts. Myers in his work, observed the samples shrinked at least $13 \%$ in $Z$ direction and $10 \%$ in $X-Y$ surface when used powder of particle size $48 \mu \mathrm{m}$ [50]. This shrinkage appears to be lower than the reported on the present work; however, the investigated spheres are hollow particles which resulted in a higher degree of shrinkage. Liravi et al. [52] showed that the shrinkage and porosity also depend on the speed of the roller and rheology of the binder on the powder surface. As smaller droplets from a medium viscous fluid can reduce the displacement of powder particles reducing porosity.

Figure $4 a$ and $b$ show some degree of porosity in both green and sintered states. However, the sintered parts showed $9.6 \%$ less porosity than the samples in the green state. It has been reported that in powders like aluminumsilicates with traces of metal oxides, the higher the sintering temperature (approaching the fusion temperature), the lower porosity, and the higher the strength achieved
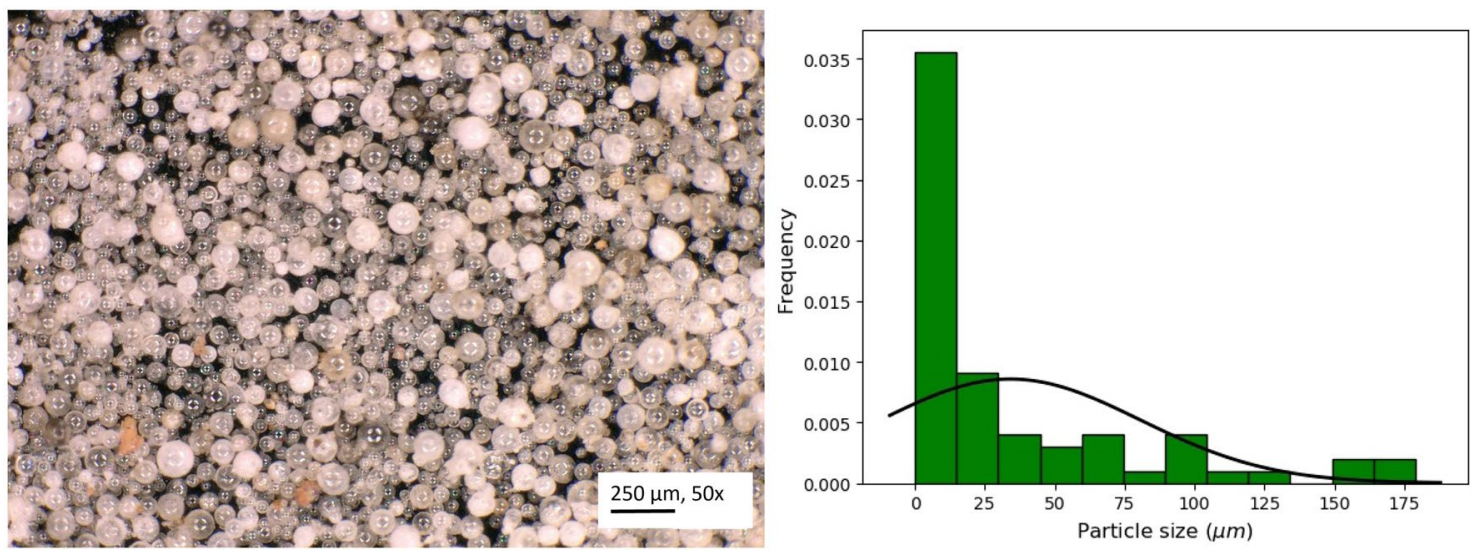

Fig. 3 Micrograph of the as-received microspheres and their particle size distribution

\section{SN Applied Sciences}


Fig. 4 Micrographs of the printed ceramic spheres. (a) Green state. (b) Sintered state. (c) Magnified picture of the sintered state showing a necking between large particles
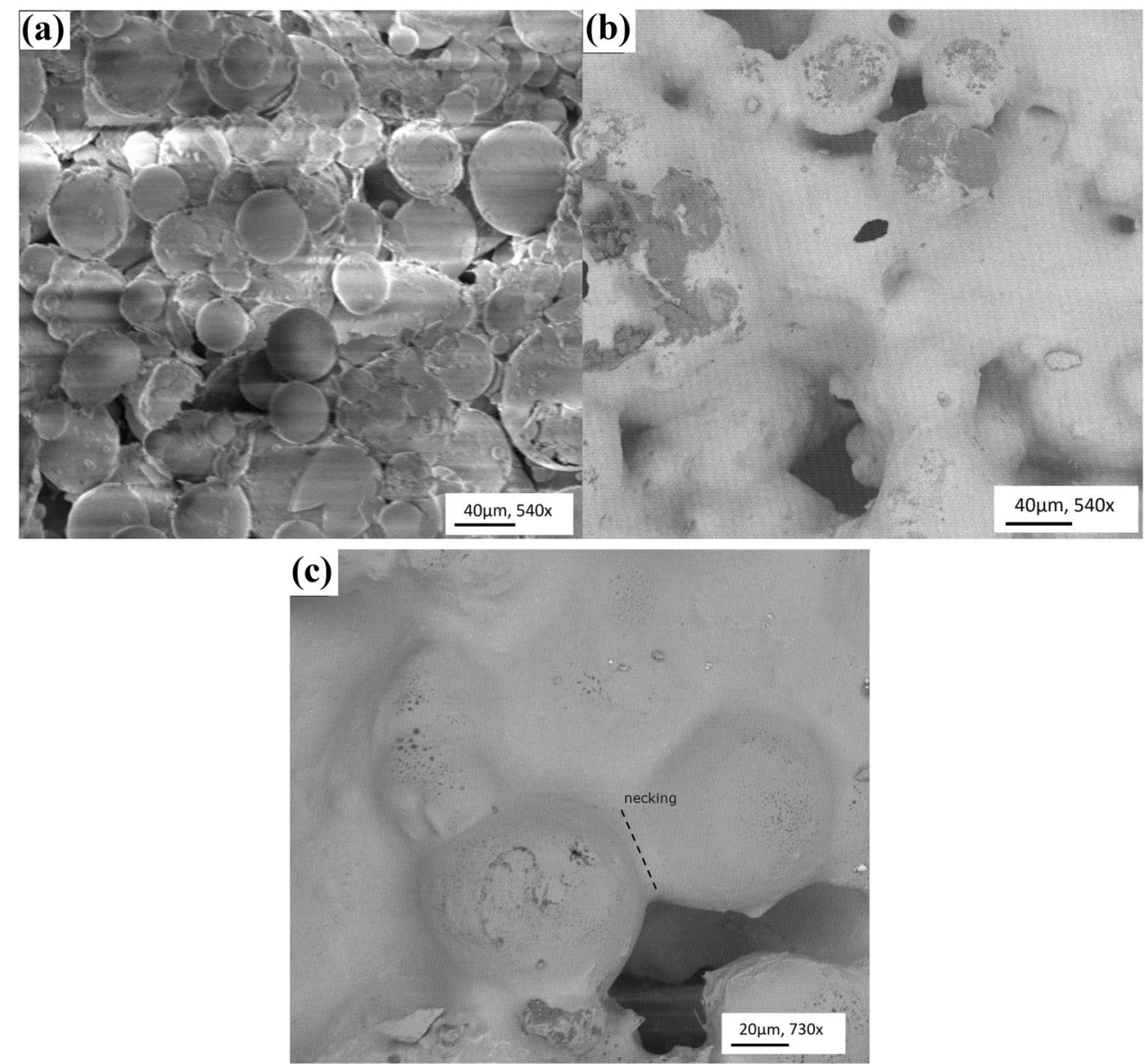

on the system [43]. This reduction of porosity seems to be associated with the particle diffusion mechanism. It is interesting to note that the average particle size on the green and sintered state increased from 47.5 to $67.9 \mu \mathrm{m}$. These features were observed via SEM micrographs and quantified using Image J. The observations revealed that smaller particles have diffused within large diameter particles (see Fig. 4). The sintered samples were then transformed into grayscale images and analyzed through the MATLAB function "graythresh" using the "im2bw" command. The final output image was constituted by 1 's and 0 's representing the solid and porous areas respectively [53]. Here, a default threshold value of 0.5 was used for the image conversion [53]. This analysis resulted in about $32 \%$ of porosity on the sintered parts. This modeling approach has been previously corroborated and validated by Kyle et al. [54], with a modeling error of $10 \%$ when predicting the mechanical performance of ceramic based materials.

XRD analysis of the sintered and green parts were also performed (see Fig. 5). From the figure, it is observed that the sintered samples display an increased degree of crystallinity to $15.1 \%$, as a result of the annealing process. The composition of the sintered parts was $63.4 \%$ Alumina, $27.5 \%$ Silica with carbon, titanium and potassium oxides

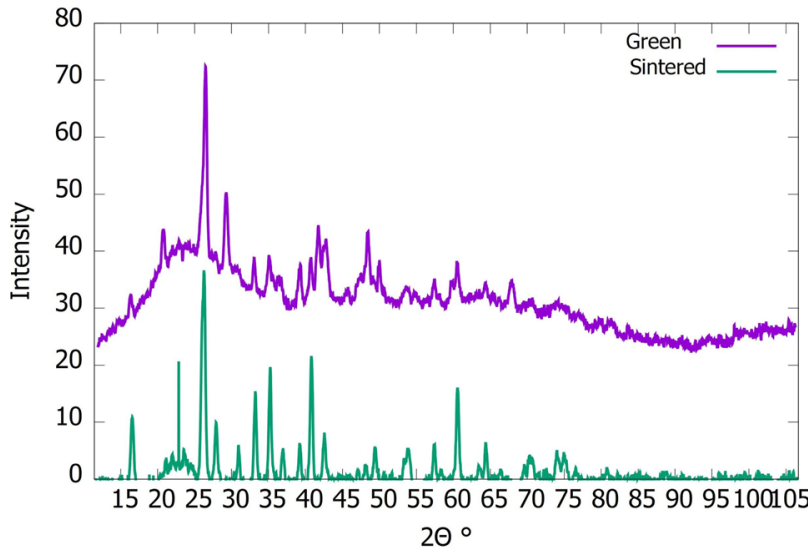

Fig. 5 XRD graph of the green and sintered samples revealing increase in crystallinity on the sintered parts (XRD peaks in the sintered state show higher intensity than in the green state)

forming the remaining $9 \%$, and transforming from sillimanite to mullite phase with an orthorhombic crystalline structure [55].

The samples for determining mechanical performance were printed in different directions while considering the shrinkage. Right angled cylinders of $12.5 \times 12.5 \mathrm{~mm}$ 
(height $x$ diameter) for compressive testing and rectangular bars of $40 \times 6 \times 5 \mathrm{~mm}$ (length $\mathrm{x}$ breadth $\mathrm{x}$ height) for flexural testing and $30 \times 5 \times 4 \mathrm{~mm}$ (length $\mathrm{x}$ breadth $x$ height) for fracture toughness determination were printed. After sintering, the samples were tested for their compressive and flexural strength. The sintered parts resulted in a compressive strength $88 \%$ higher than the observed in their green state. Compressive strength in $\mathrm{X}$, $Y$ and $Z$ directions yielded an average value of $29.7 \mathrm{MPa}$, with an overlapping on the error bars, suggesting no statistical difference across the printing directions (see Fig. 6a). The parts printed in the $Y$ direction, showed the highest averaged compressive strength, which could be associated with stronger diffusion particles in the columnar direction [56].

The flexural strength of the sintered samples yielded an average value of $9.9 \mathrm{MPa}$ (see Fig. 6b). The flexural strength seemed to be 3 times lower than the compressive strength. This may be explained by the tensile loading on the bottom part of the specimens during the flexural testing, weakening the sample and making it fail at an earlier loading stage. The strength here obtained appears to be comparable to those reported on sintered alumina and alumino-silicates [57, 58]. Myers et al. [50] reported a compressive strength of $27.9 \mathrm{MPa}$ for Silica samples printed via Binder Jetting printing. Castilho et al. [59] have shown similar mechanical properties with strength higher in $\mathrm{Y}$ direction when compared to $X$ and $Z$ directions. This is because of the directionality introduced by the printing process. Although the samples undergo a homogenous sintering thermal treatment, the microporosity and the voids still remain in the part, but with reduced radius, the effects of print direction remain. Hence, the samples printed in the testing direction resulted in higher strength.
Following the compression and flexural testing, the fractured samples were analyzed on an SEM, and it was observed that parts displayed lack of plasticity, with most of the failure mechanism located along the diffused and larger spherical particles, as well as on some isolated hollow spheres (see Fig. 7). A similar failure mode was observed in the samples printed in $X, Y$ and $Z$ directions. It seems that mechanical strength of these lightweight structures was imparted by the sintering bonding. Indeed, once the maximum stresses exceeded the modulus of rupture, an unstable failure process took place along the samples.

The fracture toughness of the samples was evaluated following the ASTM 1421. Figure 8 shows that the samples printed in the $X$ and $Y$ direction resulted in the highest specific fracture toughness when compared to those parts printed in the $Z$ direction. This could be due to the fact that fracture grows perpendicular to the layering printing process in the $\mathrm{X}$ and $\mathrm{Y}$ orientations, while in the $\mathrm{Z}$ - direction, the failure propagates parallel to the layering building sequence, which seems to be related to the weakest regions on 3D printed structures. The values presented in the $X$ and $Y$ printed direction are 30\% lower than those reported on alumina foams composed of well packed macro/micro ceramic spheres [60]. These results suggest that the inclusion of smaller sphere particles should be incorporated during the printing process so these can fillin the gaps left by the macro-spheres, reducing the outer porosity of the parts, with a probable increase on the fracture toughness.

Hardness testing was also performed on the $X-Y$ polished plane on the sintered samples $(10 \times 8 \mathrm{~mm}$ (diameter $x$ height)), and it was observed that these structures yielded a HV10 between 600 and 800 (see Fig. 9). This hardness value is $38.3 \%$ lower than that reported values in bulk mullite parts fabricated via slip casting [61].

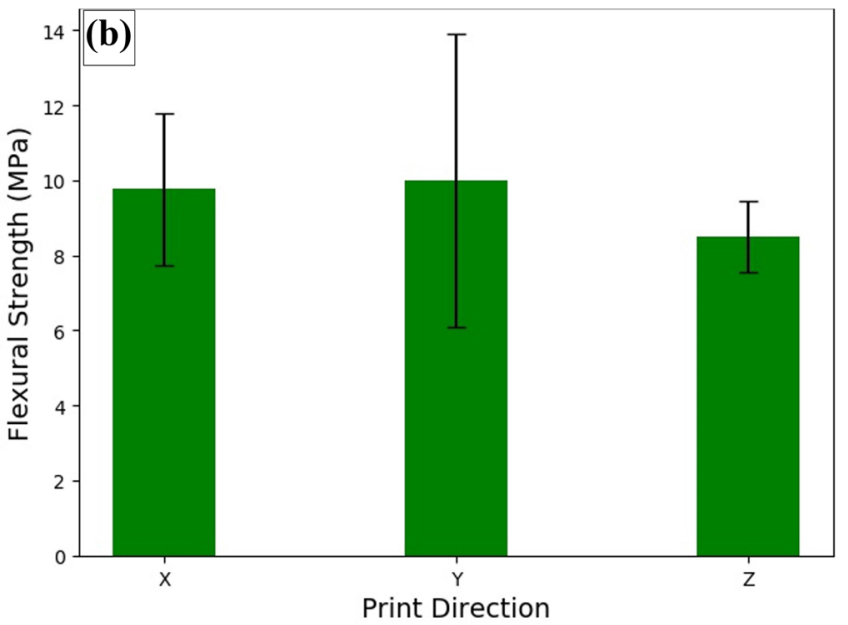

Fig. 6 Mechanical properties of the printed and sintered hollow spheres. (a) Compressive Strength. (b) Flexural strength 

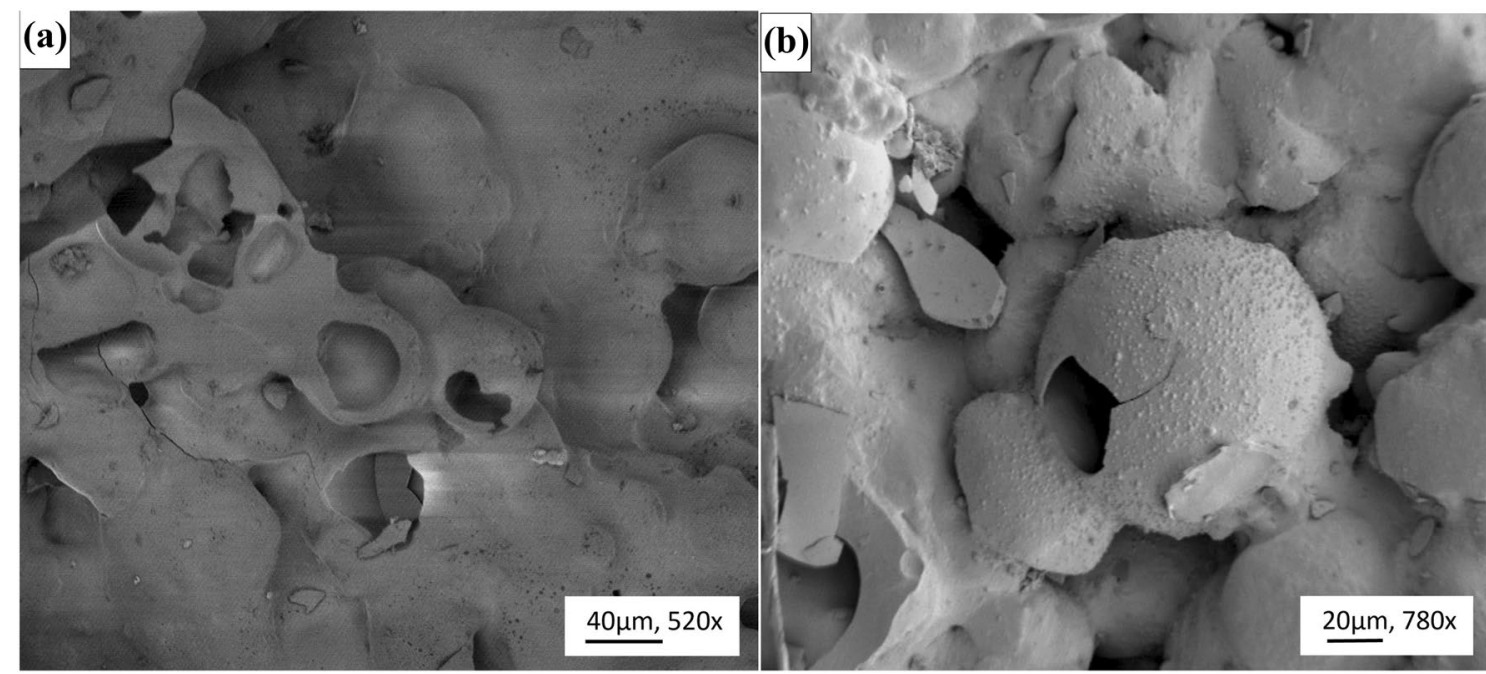

Fig. 7 SEM micrograph of fractured samples showing fracture along the sintered spherical particles

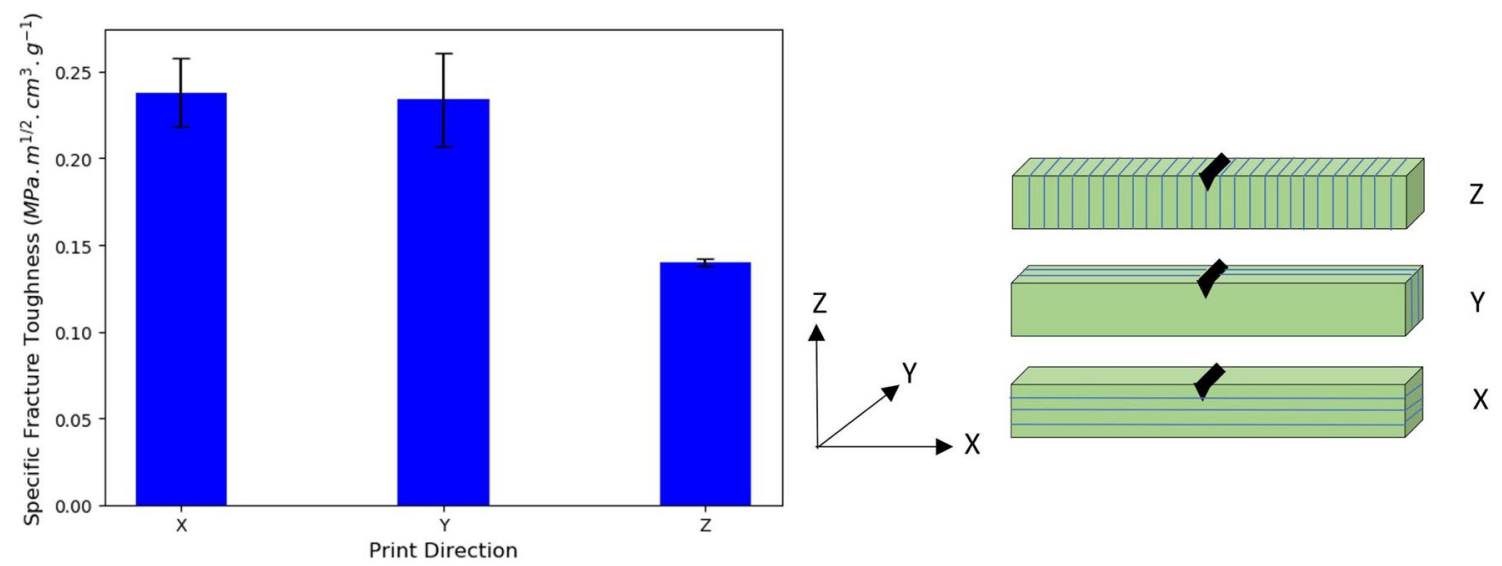

Fig. 8 Specific fracture toughness of the sintered parts printed in different directions along with the schematic diagrams of the printing directions

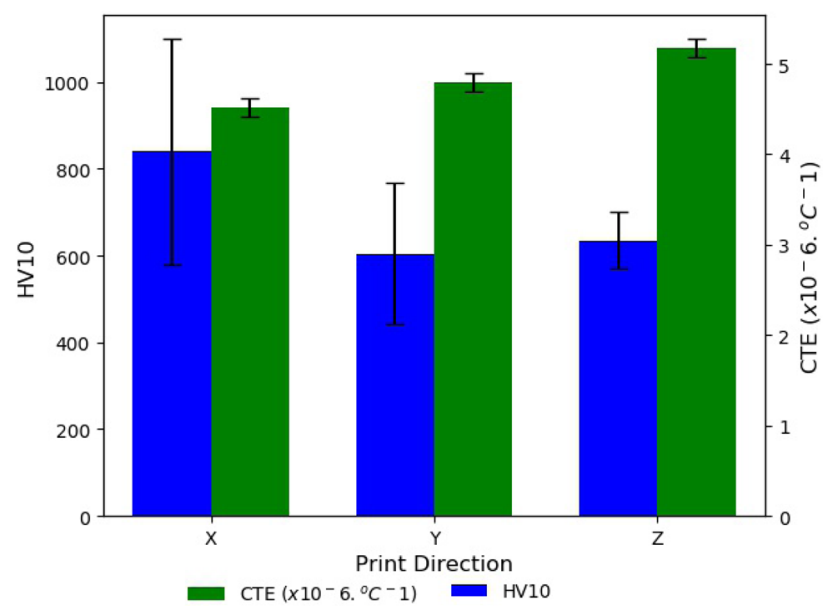

Fig. 9 Hardness and CTE values of the samples in different print directions
Figure 9 shows that standard deviation error bars overlap across the different printing orientations, suggesting that the HV10 difference is not statistically significant. The lower averaged hardness of the part printed in the $Y$ and $Z$-directions is probably due to measurements next to a pit or a layering interface. Also, the large standard deviation in the $\mathrm{X}$-direction could be influenced by the variations of porosity across the surface. Included in Fig. 9, is the Coefficient of Thermal Expansion (CTE) of the printed samples $(6 \times 5 \times 6 \mathrm{~mm}$ (length $\mathrm{x}$ breadth $x$ height)), which shows small variation across the different printing directions, suggesting that the sintered process appeared to have yielded a quasi-static thermal profile. Harrison et al. [62] have shown similar results on Invar printed in different directions. It is reported that there was no marked difference among different print 
directions and the smaller disparity was explained by bulk anisotropy. In this work a slightly higher CTE was observed in $\mathrm{Z}$ direction, and it could be accounted for the heterogeneous distribution of particles. From Fig. 9, it is observed an averaged CTE value $4.8 \times 10^{-6} \mathrm{C}^{-1}$, a value that suggests that these materials could be used as promising structures for composite tooling applications [63].

Parts printed in Z-direction were subjected to an abrasive test, and the height and volume loss was recorded at 5, 15, 30 and 60 min intervals starting with cylindrical samples of $12.6 \mathrm{~mm}$ high (see Fig. 10). The amount of material removed during the first 5 min was greater than the recorded after 30 or $60 \mathrm{~min}$ of abrasion. The initial material lost during the testing process could be associated with loosely packed particles at the surface or near the surface. After $1 \mathrm{~h}$ of abrasion the samples seem to have lost around $1 \mathrm{~mm}$ of material, which represents about $8 \%$ of volume lost and reached a plateau. The wear factor was evaluated using the following equation: $\mathrm{K}=\mathrm{W} /(\mathrm{LF})$, where $\mathrm{W}$ is the wear mass loss in $\mathrm{mg}, \mathrm{L}$ is the sliding distance in $\mathrm{m}$, which was $5666 \mathrm{~m}$ for this study, and $F$, the applied load in N [64]. It was found that after $60 \mathrm{~min}$ of abrasion, the wear factor was $0.0022 \mathrm{mg} / \mathrm{mN}$, a value that is about 5 times higher than the reported on mullite coatings [64]. However, it is worth mentioning that the applied loads by Vishwanath and Vijayarangan [64] on the mullite coating were 3 to 10 times lower than those used in the present research work. These results seem to be attractive for applications such as rotor brakes, where hardness, wear and lightweight features are critical aspects for an enhanced performance.

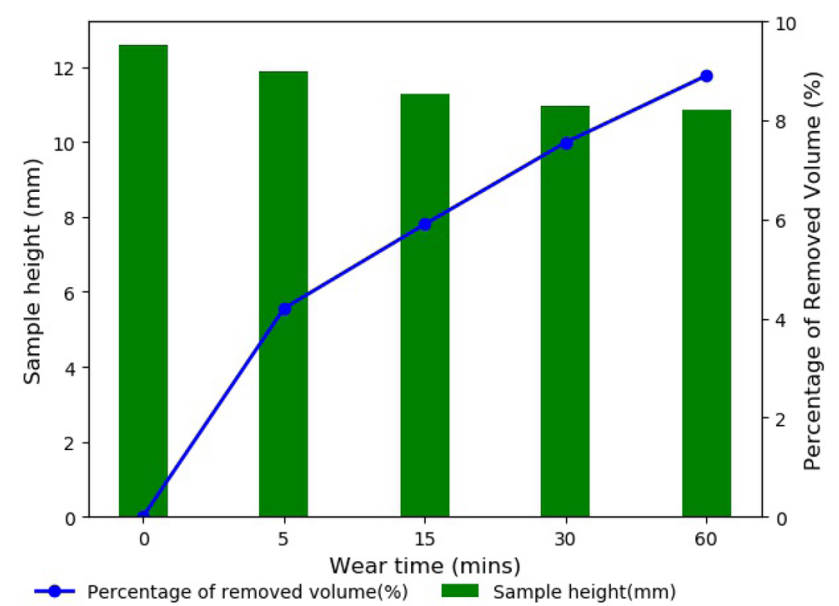

Fig. 10 Abrasive wear observed on parts printed in Z-direction after subjecting to wear at different times

\section{Conclusions}

The mechanical and thermal properties of hollow micro spherical particles printed via Binder Jetting have been investigated. The free flowing powder with low specific gravity allows a successful printing process of complex structures via BinderJetting. An averaged $27.2 \%$ of shrinkage was observed during post processing of these microspherical specimens. The work has highlighted several attributes to the proposed feedstock mechanism in obtaining strong structural components. The samples printed in this work reported an average compressive strength of $29.7 \mathrm{MPa}$, a flexural strength of 9.9 MPa and a fracture toughness of about $0.237 \mathrm{MPa} \mathrm{m}^{1 / 2}$.

1. The potential of 3D printing complex and lightweight structures capable of withstanding relatively high mechanical stresses, with the benefit of corrosion resistance. The investigated system can be an alternate material for current ceramic structures where lightweight features in conjunction with mechanical performance is required. Some specific applications include armor strike faces, coatings for re-entry vehicles, machine tools spindles, forming tools and for epoxy infiltrations.

2. A low coefficient of thermal expansion has been recorded on the investigated 3D printed material. On average, a CTE of $4.83 \times 10^{-6}{ }^{\circ} \mathrm{C}^{-1}$ has been observed in all directions. This CTE clearly suggests a potential application in the composite tooling field, durable structures, low CTE, and fast leading times are attractive traits. Current tooling composite molds have a CTE about $18 \times 10^{-6}{ }^{\circ} \mathrm{C}^{-1}$, a value 3.72 times higher than the reported on the investigated system.

3. The wear performance here reported, appeared to have yielded similar values to those recorded on alumina coating. However, the hardness of the investigated system seems to need to be improved in order to compete with those displayed by bulk ceramics. On the other hand, it is worth mentioning that the lightweight trait of these 3D printed hollow spheres is an attractive trade especially in the automotive sector in applications such as rotor brakes.

The present study has provided the thermal and mechanical platform of 3D printed parts based on hollow alumina-silicate microspheres. It is expected that this kind of materials can be used as the complex lightweight components in the automotive, aerospace, tooling and surface coating refractory sectors.

The future studies are concentrated on printing complex structural lattices based on spatially graded 
configurations and their transformation into Interpenetrated Ceramic composites using a reaction metal penetration technology. We expect this upcoming study can provide outstanding mechanical performance, especially for impact and wear applications.

Acknowledgements We would like to thank the Friedman Endowment for Manufacturing at Youngstown State University for supporting this project.

\section{Declarations}

Conflict of interest The authors of the present work express no conflict of interest.

Open Access This article is licensed under a Creative Commons Attribution 4.0 International License, which permits use, sharing, adaptation, distribution and reproduction in any medium or format, as long as you give appropriate credit to the original author(s) and the source, provide a link to the Creative Commons licence, and indicate if changes were made. The images or other third party material in this article are included in the article's Creative Commons licence, unless indicated otherwise in a credit line to the material. If material is not included in the article's Creative Commons licence and your intended use is not permitted by statutory regulation or exceeds the permitted use, you will need to obtain permission directly from the copyright holder. To view a copy of this licence, visit http://creativecommons .org/licenses/by/4.0/.

\section{References}

1. Barber RF (1999) Lightweight composite material comprising hollow ceramic microspheres. US Patent 5,935,699

2. Kuang X, Carotenuto G, Nicolais L (1997) A review of ceramic sintering and suggestions on reducing sintering temperatures. Adv Perform Mater 4:257-274

3. Freiman SW, Fong JT (2013) Chapter 9.4-Determination of the mechanical reliability of brittle materials. In: Somiya S (ed) Handbook of advanced ceramics (Second Edition). Academic Press, Oxford, pp 675-680

4. Kim S-S, Kim S-T, Ahn J-M, Kim K-H (2004) Magnetic and microwave absorbing properties of $\mathrm{Co}-\mathrm{Fe}$ thin films plated on hollow ceramic microspheres of low density. J Magn Magn Mater 271:39-45

5. ISO/TC ISO/ASTM 52900:2015 (ASTM F2792) Additive manufacturing -- General principles -- Terminology. In: https://www. iso.org/standard/69669.html. https://www.iso.org/obp/ui/. Accessed 22 Apr 2019

6. Melcher R, Martins S, Travitzky N, Greil P (2006) Fabrication of Al2O3-based composites by indirect 3D-printing. Mater Lett 60:572-575

7. Deckers J, Vleugels J, Kruth J-P (2014) Additive manufacturing of ceramics: a review. J Ceram Sci Technol 5:245-260

8. Bose S, Vahabzadeh S, Bandyopadhyay A (2013) Bone tissue engineering using 3D printing. Mater Today 16:496-504

9. Yang L, Miyanaji H (2017) Ceramic additive manufacturing: a review of current status and challenges. In: Proceedings of the 28th annual international solid freeform fabrication symposium. pp 653-679
10. Leong SS, Yee YW, Edith WF et al (2017) Direct selective laser sintering and melting of ceramics: a review. Rapid Prototyp J 23:611-623

11. Balla VK, Bose S, Bandyopadhyay A (2008) Processing of bulk alumina ceramics using laser engineered net shaping. Int J Appl Ceram Technol 5:234-242

12. Kunchala $P$, Kappagantula K (2018) 3D printing high density ceramics using binder jetting with nanoparticle densifiers. Mater Des 155:443-450

13. Zhao X, Evans JRG, Edirisinghe MJ, Song J-H (2002) Direct ink-jet printing of vertical walls. J Am Ceram Soc 85:2113-2115

14. Mitteramskogler G, Gmeiner R, Felzmann R et al (2014) Light curing strategies for lithography-based additive manufacturing of customized ceramics. Addit Manuf 1-4:110-118

15. Halloran JW (2016) Ceramic stereolithography: additive manufacturing for ceramics by photopolymerization. Annu Rev Mater Res 46:19-40

16. Zocca A, Colombo P, Gomes CM, Günster J (2015) Additive manufacturing of ceramics: issues, potentialities, and opportunities. J Am Ceram Soc 98:1983-2001

17. Yves-Christian H, Jan W, Wilhelm M et al (2010) Net shaped high performance oxide ceramic parts by selective laser melting. Phys Procedia 5:587-594

18. Wilkes J, Hagedorn Y, Meiners W, Wissenbach K (2013) Additive manufacturing of $\mathrm{ZrO} 2$-Al $2 \mathrm{O} 3$ ceramic components by selective laser melting. Rapid Prototyp J 19:51-57

19. Travitzky N, Bonet A, Dermeik B et al (2014) Additive manufacturing of ceramic-based materials. Adv Eng Mater 16:729-754

20. (2015) ISO 17296-2:2015. In: ISO. https://www.iso.org/stand ard $/ 61626$. html?browse $=$ tc. Accessed 9 Jan 2020

21. sphereone.net Extendospheres++TG+2019.pdf. Extendospheres ${ }^{\circledR}$ TG Hollow Spheres

22. Green DJ (1985) Fabrication and mechanical properties of lightweight ceramics produced by sintering of hollow spheres. J Am Ceram Soc 68:403-409

23. Suryavanshi AK, Swamy RN (2002) Development of lightweight mixes using ceramic microspheres as fillers. Cem Concr Res 32:1783-1789

24. Tao XF, Zhang LP, Zhao YY (2009) Al matrix syntactic foam fabricated with bimodal ceramic microspheres. Mater Des 30:2732-2736

25. Hu J, Chen M, Fang X, Wu L (2011) Fabrication and application of inorganic hollow spheres. Chem Soc Rev 40:5472-5491

26. Semenov V, Rozovskaya T, Oreshkin DV (2014) Properties of the dry masonry mixtures with hollow ceramics microspheres. In: Xu Q, Li Y, Yang X (eds) Advanced materials research. Trans Tech Publ, Switzerland, pp 1244-1247

27. Binner J (2005) Ceramics foams. In: Scheffler M, Colombo P (eds) Cellular ceramics. Wiley-VCH Verlag GmbH \& Co, KGaA, Weinheim, FRG, pp 31-56

28. Balch DK, O'Dwyer JG, Davis GR et al (2005) Plasticity and damage in aluminum syntactic foams deformed under dynamic and quasi-static conditions. Mater Sci Eng, A 391:408-417

29. Santa Maria JA, Schultz BF, Ferguson JB et al (2014) Effect of hollow sphere size and size distribution on the quasi-static and high strain rate compressive properties of Al-A380-Al2O3 syntactic foams. J Mater Sci 49:1267-1278

30. Balch DK, Dunand DC (2006) Load partitioning in aluminum syntactic foams containing ceramic microspheres. Acta Mater 54:1501-1511

31. Liu Q, Zi Z, Zhang M et al (2013) Solvothermal synthesis of hollow glass microspheres/Fe3O4 composites as a lightweight microwave absorber. J Mater Sci 48:6048-6055

32. Huo W, Zhang X, Chen Y et al (2018) Novel mullite ceramic foams with high porosity and strength using only fly ash hollow spheres as raw material. J Eur Ceram Soc 38:2035-2042 
33. Jiang B, Blugan G, Sturzenegger PN et al (2016) Ceramic spheres-a novel solution to deep sea Buoyancy modules. Materials 9:529. https://doi.org/10.3390/ma9070529

34. Schneider H, Schmüker M, MacKenzie KJD (2005) Basic properties of mullite. In: Schneider H, Komarneni S (eds) Mullite. Wiley-VCH Verlag GmbH \& Co, KGaA, Weinheim, FRG, pp 141-225

35. Bernardo E, Colombo P, Pippel E, Woltersdorf J (2006) Novel mullite synthesis based on alumina nanoparticles and a preceramic polymer. J Am Ceram Soc 89:1577-1583

36. Hossain KMZ, Patel U, Ahmed I (2015) Development of microspheres for biomedical applications: a review. Prog Biomater 4:1-19

37. Anggono J (2005) Mullite ceramics: its properties structure and synthesis. Jurnal Teknik Mesin 7:1-10

38. Goodridge RD, Dalgarno KW, Wood DJ (2006) Indirect selective laser sintering of an apatite-mullite glass-ceramic for potential use in bone replacement applications. Proc Inst Mech Eng H 220:57-68

39. Briselden TD, Reilly TM, Forsman DR (2010) 3-D Printing of near net shape products. US Patent 20100279007:A1

40. Yoo, J. Cima, M.J. Khanuja, S. E.M., Sachs (2018) Structural ceramic components by 3D printing. In: Solid freeform fabrication symposium. The University of Texas at Austin, pp 40-50

41. Spoerk M, Savandaiah C, Arbeiter F et al (2019) Optimization of mechanical properties of glass-spheres-filled polypropylene composites for extrusion-based additive manufacturing. Polym Compos 40:638-651

42. Krenzel TF, Schreuer J, Laubner D et al (2019) Thermo-mechanical properties of mullite ceramics: new data. J Am Ceram Soc 102:416-426

43. Chandra D, Das GC, Sengupta U, Maitra S (2013) Studies on the reaction sintered zirconia-mullite-alumina composites with titania as additive. Cerâmica 59:487-494

44. Enneti RK, Prough KC (2019) Effect of binder saturation and powder layer thickness on the green strength of the binder jet 3D printing (BJ3DP) WC-12\% Co powders. Int J Refract Metal Hard Mater 84:104991

45. Sachs EM, Cima MJ, Caradonna MA, et al (2003) Jetting layers of powder and the formation of fine powder beds thereby. US Patent 6596224B1

46. Du W, Singh M, Singh D (2020) Binder jetting additive manufacturing of silicon carbide ceramics: development of bimodal powder feedstocks by modeling and experimental methods. Ceram Int 46:19701-19707

47. Miyanaji H, Orth M, Akbar JM, Yang L (2018) Process development for green part printing using binder jetting additive manufacturing. Front Mech Eng Chin 13:504-512

48. Sacks MD, Bozkurt N, Scheiffele GW (1991) Fabrication of mullite and mullite-matrix composites by transient viscous sintering of composite powders. J Am Ceram Soc 74:2428-2437

49. Bordia RK, Kang S-JL, Olevsky EA (2017) Current understanding and future research directions at the onset of the next century of sintering science and technology. J Am Ceram Soc 100:2314-2352
50. Myers K Structure-Property Relationship of Binder Jetted Fused Silica Preforms to Manufacture Ceramic-Metallic Interpenetrating Phase Composites. Doctor of Philosophy, Youngstown State University

51. Parab ND, Barnes JE, Zhao C et al (2019) Real time observation of binder jetting printing process using high-speed $\mathrm{X}$-ray imaging. Sci Rep 9:2499

52. Liravi F, Vlasea M (2018) Powder bed binder jetting additive manufacturing of silicone structures. Addit Manuf 21:112-124

53. Andreassen E, Andreasen CS (2014) How to determine composite material properties using numerical homogenization. Comput Mater Sci 83:488-495

54. Myers K, Juhasz M, Cortes P, Conner B (2015) Mechanical modeling based on numerical homogenization of an Al2O3/Al composite manufactured via binder jet printing. Comput Mater Sci 108:128-135

55. Wondraczek L, Heide G, Kilo M et al (2002) Computer simulation of defect structure in sillimanite and mullites. Phys Chem Miner 29:341-345

56. Farzadi A, Solati-Hashjin M, Asadi-Eydivand M, Abu Osman NA (2014) Effect of layer thickness and printing orientation on mechanical properties and dimensional accuracy of 3D printed porous samples for bone tissue engineering. PLoS ONE 9(9):e108252

57. Du W, Ren X, Ma C, Pei Z (2019) Ceramic binder jetting additive manufacturing: particle coating for increasing powder sinterability and part strength. Mater Lett 234:327-330

58. Snelling DA, Williams CB, Suchicital CTA, Druschitz AP (2017) Binder jetting advanced ceramics for metal-ceramic composite structures. Int J Adv Manuf Technol 92:531-545

59. Castilho M, Dias M, Gbureck U et al (2013) Fabrication of computationally designed scaffolds by low temperature 3D printing. Biofabrication 5(3):035012

60. Salvini VR, Pandolfelli VC, Spinelli D (2018) Mechanical properties of porous ceramics. In: AI-Naib UMB (ed) Recent advances in porous ceramics. IntechOpen, London

61. Pitchford JE, Stearn RJ, Kelly A, Clegg WJ (2001) Effect of oxygen vacancies on the hot hardness of mullite. J Am Ceram Soc 84:1167-1168

62. Harrison NJ, Todd I, Mumtaz K (2017) Thermal expansion coefficients in Invar processed by selective laser melting. J Mater Sci 52:10517-10525

63. Cortes P, Maravola M, Conner B, et al (2019) Production of Low Coefficient of Thermal Expansion Composite Tooling Manufactured Via 3D Printing. In: SAMPE 2019 - Charlotte, NC

64. Viswanath B, Vijayarangan S (2010) A study of the low stress sliding abrasion wear behaviour of mullite coatings. Int J Mech Mater Eng 5(6):106-111

Publisher's Note Springer Nature remains neutral with regard to jurisdictional claims in published maps and institutional affiliations. 